\section{EMBRYRIDDLE \\ Aeronautical University}

SCHOLARLY COMMONS

\section{International Journal of Aviation,} Aeronautics, and Aerospace

\title{
Low Level Turbulence Detection For Airports
}

Anthony O' Connor

Dublin Institute of Technology, anthony260610@gmail.com

Derek Kearney

Dublin Institute of Technology, derek.kearney@dit.ie

Follow this and additional works at: https://commons.erau.edu/ijaaa

Part of the Aviation Safety and Security Commons, and the Navigation, Guidance, Control and Dynamics Commons

\section{Scholarly Commons Citation}

O' Connor, A., \& Kearney, D. (2019). Low Level Turbulence Detection For Airports. International Journal of Aviation, Aeronautics, and Aerospace, 6(1). https://doi.org/10.15394/ijaaa.2019.1302

This Position Paper is brought to you for free and open access by the Journals at Scholarly Commons. It has been accepted for inclusion in International Journal of Aviation, Aeronautics, and Aerospace by an authorized administrator of Scholarly Commons. For more information, please contact commons@erau.edu. 


\section{Low Level Turbulence Detection For Airports}

\section{Cover Page Footnote}

The research reported in this paper is supported by Dublin Institute of Technology and the Energy Resource Group. The wind velocity data provided for the study was provided by the Energy Research Group and Dr Derek Kearney. The Author would like to thank the researchers in the ERG for their support and in particular Dr Derek Kearney for assisting with this paper. 


\section{INTRODUCTION}

Low-level wind shear can affect aircraft performance and has potentially adverse effects on flight safety during landing and take-off phases. Providing immediate and accurate data relating to all prevailing wind conditions including Low-level wind shear on the runway is crucial for approaching aircraft. Providing the pilot with a complete and comprehensive analysis of wind conditions will facilitate the pilot's decision to land or to go-around. The problem caused by low-level wind shear on aircraft is well documented and recognized in literature - the aviation industry concluded that the majority of accidents that occurred over the past 10 years have occurred during the approach, landing, and go-around flight phases. At the go-around safety forum in Brussels in 2013, it was concluded that due to rapid changing weather and runway conditions, a pilot does not always have the latest information on which to make a landing or go-around decision (Eurocontrol, 2013).

Current methods of wind shear calculations involve data from an aircraft on descent and recording data from different anemometers spaced at different levels along a runway on mast. The limitation in this approach is that the calculation of wind shear from two winds separated by a distance gives the overall wind shear between those two points. The information does not indicate if the rate of shear is linear or where most of the shear occurs between the points sampled. It is wholly inadequate and does not give the maximum shear (International Civil Aviation Organization [ICAO], 2005).

This would indicate that traditional meteorological instrumentation used in the aviation industry is not adequately providing all the necessary data required by the air traffic controllers and flight crew with the information that is critically needed on approach and landing, needed for the greatest safety of passengers and crew. It must be noted that despite the recent advances in wind measuring techniques using Lidar, Sodar, Doppler, and Low-level Wind Shear Alert Systems (LLWAS), there is no satisfactory way of measuring turbulence or wind shear to date from the ground as noted in ICAO (2007) Annex 3.5.6.3. Based on the foregoing and research of continuing aircraft accidents to date, there is a requirement for a new instrument, capable of recording highfrequency variations in wind speed, direction, and turbulence. These researchers put forth the position that a solution to the problem of forecasting low-level wind shear and turbulence for the approach, landing, and take-off of aircraft could be addressed by incorporating the Wind Urchin as part of the LLWAS in all airports.

\section{LOW-LEVEL WIND SHEAR}

Low-level wind shear can affect aircraft performance and has potentially adverse effects on flight safety during landing and take-off phases. Wind shear is the sudden change in velocity and/or direction of wind speed over a small 
area, where layers or columns of air with different velocities flow to adjacent layers or columns. Wind shear of itself is not categorized as turbulence but when it occurs the different turbulence categories may become applicable. Low-level wind shear is associated with thunderstorms, frontal systems, temperature inversions, and strong upper level winds exceeding $25 \mathrm{kt}$. Wind shear can occur at any level but it is the occurrence of low-level wind shear below 500 meters that is especially hazardous to aircraft during landing and take-off phases. During the take-off and approach phases of the flight, the aircraft's speed and height are near critical values and because of the aircraft's close proximity to the ground, the pilot has to react immediately to iniate counter measures to maintain control of the aircraft.

An aircraft taking off could experience a headwind producing lift for the aircraft then this suddenly changes to a downdraught followed by a tailwind which could lead to a loss of hight if not countered causing the aircraft to crash into the ground. The Federal Aviation Administration's (FAA) pilots handbook states that wind only affects ground speed and drift (FAA, 2016). However, in the case of wind shear, there are sudden changes in velocity and direction. It can be stated that wind has a transient effect on airspeed in which the aircraft will seek to restore its original trimmed airspeed. The most severe type of wind shear is a microburst. A microburst is defined as a downdraught that induces a sudden outflow of damaging horizontal winds at the surface which can extent between 0.4 and $4 \mathrm{~km}$ in distance and has a nominal depth of $300 \mathrm{~m}(1000 \mathrm{ft})$.

The lifespan of a microburst is approximately 5-15 minutes and can produce downdraughts of $2000 \mathrm{~m}(6000 \mathrm{ft})$ per minute with headwind losses of between 30-90 kt. Microbursts are associated with rain, convective cloud, and thunderstorms. The small scale of the microburst in both space and time makes it extremely difficult to predict.

The FAA, ICAO, and other aviation bodies have invested signifigant resoursces into microburst detection systems. The main systems currently installed at all major airports in the US are the LLWAS, Terminal Dopler Weather Radar (TDWR), ASR-9 ,Weather System Processor (WSP), and Light Detection and Ranging (LIDAR). These detection systems will be discussed in more detail. Since 1943, there have been over 1500 fatalities attributed to wind shear (Aviation Safety Network, 2018). There has been a marked reduction in the number of aviation accidents attributed to wind shear over the past decade as a result of the measures and resouces invested in wind shear detection systems and also better pilot training in the area of identifying and countering wind shear occurances. However only as recent as 2016, a modern Boeing 737 aircraft crashed with the loss of all souls on board after encountering wind shear while attempting to land in Russia. Wind shear and low-level turbulence will always be a serious hazard for aviation and a potential killer, and there must be continued vigilance, continued research, and improvements in new systems to detect these occurances providing real time information to pilots. Continued 
pilot training on wind shear counter measures and go-around procedures should involve ongoing and refresher courses for all pilots.

\section{Low-level Wind Shear Alert Systems}

One of the main ways to measure LLWS around the airport runway is to install a series of wind sensors either side of the runway path and extended boundary to around 3 nautical miles from the ends of the runway. This system is known as a Low-level Wind Shear Alert System (LLWAS). A typical LLWAS system uses a network of anemometers mounted on masts which are strategically located around the airfield with one centre field sensor that are connected to a digital processor with visual and audible warning indicators. An airport may have from 6 to 32 sensors depending on the environmental conditions present and requirements.

The remote sensing stations comprise of anemometers mounted on poles at a height of between 10-15 m which are connected to a master station which is interfaced to the Airport Weather Observation System (AWOS). Here the data from the remote stations is processed using wind shear, microburst and gust algorithms to provide the Air Traffic Control (ATC) with wind speed, wind direction, and type and severity of wind occurrences as they relate to specific areas along the runway. The wind data from the remote stations is processed every 10 seconds to measure any wind differences between stations along the runway. The system works by calculating headwind difference between adjacent anemometers or divergence/convergence within areas bounded by the anemometers. The system then calculates loss or gains in wind speed and generates Wind Shear or Microburst warnings based on the data recorded. The system will also identify the location along the runway or airfield where the event is forecast (Gill Instruments, 2018).

The linear averaged wind measurements is calculated using a predefined parameter number of one second independent wind sensor samples. Calculation of these measurements is based on the following equation:

\section{Eqt 1:}

$$
\mathrm{X}=(1 / \mathrm{n}) * \sum \mathrm{x}_{\mathrm{i}}
$$

For all i from 1 to $n$

$\mathrm{X}_{\mathrm{i}}=\quad$ set of one second wind samples

$\mathrm{n}=\quad$ total number of wind samples

These linear measurements are inputs into the gust algorithm. They are also used for the threshold wind and centre field wind calculations. This method 
assumes a very short (less than one second) time constant for the wind sensor and electronics to acquire and digitize the wind sensor signals. The LLWAS system utilizes the FAA certified phase 3 algorithm which provides a probability of microburst detection of greater than $90 \%$ with a false alarm rate of less than 10\% (Allweatherinc, 2018). In an ICAO Wind Shear workshop report for the Centre for Australian Weather and Climate Research (CAWCR), the LLWAS system prediction of detection (POD) was stated to be $95 \%$ to $97 \%$ for microburst events within the network (CAWCR, 2010).

\section{Terminal Doppler Weather Radar}

Terminal Doppler Weather Radar's purpose is to protect the runways and terminal area of the airport and so need careful positioning relative to the airport and runways. Doppler radars are installed at most large commercial airports around the world. The radar scans the approach and departure corridors for incoming and outgoing flights. They provide coverage of microburst detection out to $20 \mathrm{~km}$ from the radar every 1 minute with wind shear detection out to $60 \mathrm{~km}$ every 6 minutes (WMO, 2016). The TDWR uses low elevation scans for the lowest 100-300 $\mathrm{m}$ from the surface. TDWR has the ability to measure the approach or departing speed of rain drops. TDWR is designed to detect wind shear and microbursts associated with convective storms. Precipitation intensity or rain drop intensity is measured by a ground-based radar that emits a very short pulse of electromagnetic wave at approximately the speed of light. As the wave encounters precipitation, part of the wave is bounced or reflected back to the radar. This is known as the echo. The strength of the returning signal or echo intensity is directly proportional to the size and quantity of the target in a given area. The echo intensity also known as the reflectivity and is measured in decibels (dBZ). Reflectivity is the amount of power bounced back to a radar from a target compared to a set point target power density at a distance of 1 meter from the radar. The reflective signal is received by the radar during its listening period. The software analyses the strength of reflected signal, the time it took to return, and the frequency shift of the pulse. The ability to detect the shift in frequency of the pulse is what makes this a Doppler radar. The TDWR computer then measure the frequency change of the reflected pulse, the velocity of the target either away or towards the radar can be calculated from analysing this frequency change. This data is then used to calculate the speed of the wind. The computer software is then able to generate a reflectivity image map of each of the three different tilt angles of the radar. The reflective image map results are displayed on a monitor in the ATC within 30 seconds after detection (Cho, 2010).

The TDWR issues a microburst detection alert, when the maximum velocity differential is more than $8 \mathrm{~m} / \mathrm{s}$ or $15 \mathrm{kt}$, when the area of the microburst is more than $3 \mathrm{~km}^{2}$ and where the maximum rate of change of the Doppler velocity is more than $5.6 \mathrm{~m} / \mathrm{s} / \mathrm{km}$. A wind shear alert is issued when the wind 
velocity difference of both sides of the shear line is more than $5 \mathrm{~m} / \mathrm{s}$ or $9 \mathrm{kt}$, the length of the shear line is more than $10 \mathrm{~km}$ and the maximum radial of the shear line is more than $2 \mathrm{~m} / \mathrm{s} / \mathrm{km}$.

\section{Doppler lidar.}

Doppler radar operates on a similar principle to that of TDWR but with a much shorter wavelength of 2 micrometres compared to a few centimetres of the radar. The Lidar emits infrared light pulses which is transmitted at a frequency of $500-750 \mathrm{~Hz}$.

Unlike the TDWR which receives the echo from rain drops, the Lidar gets its reflection from particles of dust or aerosols in the air. The shift in frequency of the return echo or reflective signal is proportional to the movement of the aerosols. The shift in frequency of the return echo is proportional to the movement of the aerosols. The quicker the aerosols move, the larger the frequency shift will be. This enables the velocity and strength of the wind to be calculated. Lidar works best in dry conditions in the presence of aerosols that provide effective back scattering. Doppler Lidar can perform sector scans at different elevation angles along the approach and landing corridors of airport runways out to about 3 nautical miles.

Doppler Lidar systems work best in dry fine weather, it is not suitable for detecting wind movement inside a thunderstorm due to the absorption of infrared light by rain drops. Lidar as a single sensor system is not suitable for microburst detection and has a lower POD in comparison to TDWR in areas where wet conditions prevail. Lidar does not have enough range coverage in humid and rainy situations and there can be missed wind shear events between scans (Chan, 2005). Lidar is not suitable for gust front protection as its range is at best $15 \mathrm{~km}$ and the gust front interest area is $18 \mathrm{~km}$ around the airport (Cho, 2010). The $18 \mathrm{~km}$ extent of gust front coverage relates to the distance a gust front would travel at $15 \mathrm{~m} / \mathrm{s}$ in 20 minutes which is considered an appropriate lead time for an airport operational alert. In a study carried out at Lincoln Laboratory's, it was concluded that a combination or Lidar and TDWR or weather radar is projected to form the best microburst detection probability (John \& Cho, 2008).

\section{Weather surveillance radar.}

The Nexrad or Weather Surveillance Radar, 1988 Doppler (WSR-88D) is one of the most advanced operational weather radar systems in the world. The WSR-88D form a network of 160 radar systems operating 24/7 in the US today (National Oceanic and Atmospheric Administration [NOAA], 2018). The network is a tri-agency administered operation comprising of the National Weather Service, FAA, and Defence Department. The project's function is to 
support weather warning and forecast missions to the three agencies as well as providing real time data for U.S. universities and commercial weather services. The WSR-88D has been constantly upgraded and updated since its first installation in 1992. The WSR-88D like all radar systems consists of three main modules, the Radar Data Acquisition (RDA), the Radar Product Generator, and the end user display systems (NOAA, 2018). The RDA provides for the detection and measurement of weather data. The RDA comprises of all the relevant hardware, firmware, and software to operate and drive the antenna, transmitter, receiver, and signal processor. The radar is an S-Band coherent machine operating at a frequency of $2700-3000 \mathrm{MHz}$, wavelength of $10.5 \mathrm{~cm}$ on an angular resolution of $0.925^{\circ} \times 0.9258^{\circ}$ (azimuth $x$ elevation), with a pulse width of $1.6 \mu$ s operating at a power of $750 \mathrm{KW}$. In 2011, all WSR-88D units were upgraded to enable dual polarization capability. Dual polarization radar system can transmit horizontal and vertical polarized pulses simultaneously. Sampling the echoes along the horizontal and vertical plane provides far more accurate measurement of precipitation as well as hail and tornado debris detection. During normal operation the radar is constantly rotating and scanning the atmosphere using a program called Volume Coverage Pattern (VCP). The VCP rotates the beam through $360^{\circ}$ in the azimuth through an elevation range of $0.5^{\circ}$ to $19.5^{\circ}$ above the horizon. In 2011 the WSR-88D had the Velocity Azimuth Display Wind Profile (VWP) product upgraded. The VWP product provides a time verses height wind profile for the volume above the radar location. Figure 1 illustrates a VWP for each elevation against range and height. 


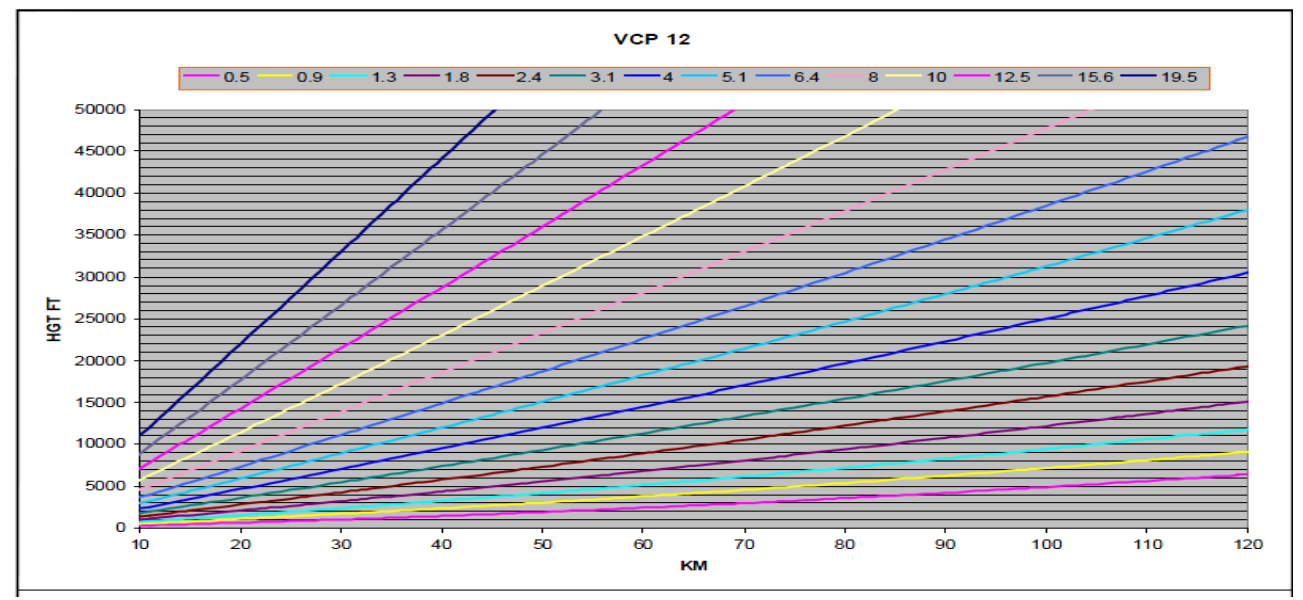

Figure 1. VCP Elevations Plotted on Range/Height Grid. Adapted from "Improving the VWP," by the National Weather Service, 2013. Retrieved from https://www.roc.noaa.gov/ wsr88d/PublicDocs/ NNOW/NNDec2010/3-5.pdf

A wind estimate is derived from an algorithm for each VWP height. Each VCP is designed to optimize the detection and sampling of weather data. In autumn of 2014, VCP 12 was updated to the WSR-88D systems with the first priority of the project being to reduce volume scan completion times and provide for faster Low-level elevation scan updates. The problem of the WSR88D slow update rates was highlighted in a study doing a comparative analysis of terminal wind shear detection systems (Cho, 2010) where it was stated that NEXRADs were no longer suitable for microburst detection and warning, because the update rates of more than 5 minutes were too slow to meet the FAA requirement. The FAA used them for gust front detection and tracking as the update rates are adequate for this type of operation. Since the implementation of VCP 12, the volume scan completion time has been reduced to 4.1 minutes. Despite the scan rate update time being reduced from nearly 6 minutes to 4.1 minutes, the WSR-88D radar will not detect all microburst occurrences at their maximum divergent intensity as this update time is still too slow, because microbursts in nature are short-lived entities lasting 3 to 5 minutes. Despite this fact, the VCP 12 is the coverage pattern of choice of the FAA because of the overlapping Low-level beams in the vertical and the relatively rapid update rate of 4.1 minutes VWP for each elevation against range and height (U.S. Department of Commerce, 2006). The WSR-88D as a single sensor system in many cases is not suitable for microburst detection at airports but combined with LIDAR would exceed the FAA requirement of a POD of $90 \%$. For single sensor case the only radar capable of meeting microburst detection is the TDWR (John \& Cho, 2008). 


\section{WIND URCHIN}

The Wind Urchin is a multidirectional anemometer which measures wind in 3D using 64 pitot tubes mounted and spaced equally around the surface of a sphere-shaped hardened plastic moulded design. The Wind Urchin can sample at frequencies up to $3,000 \mathrm{~Hz}$ providing three-dimensional data on wind speed and direction. This unique design gives the Wind Urchin the ability to measure wind shear, wind veer, and low-level turbulence. The Wind Urchin can output in digital or analogue format enabling the device to be integrated into a LLWAS at airport runways. It has been shown and discussed in previous chapters that despite advances in LLWAS technology, there continue to be air accidents as a result of low-level wind shear during the take-off and landing stages of flights. The integration of the Wind Urchin into a LLWAS could give greater accuracy of wind speed, direction, and the presence of low-level wind shear. The 3D capability of the Wind Urchin can measure and illustrate wind data in three dimensions. Because of the increased sampling rate of the Wind Urchin, wind data can be recorded at a frequency of $100 \mathrm{~Hz}$ producing 64,000 data points per second producing a greater number of samples than any other anemometer currently used in aviation for a specific timeframe. The device has a wide measuring range to measure wind speed from $0-250 \mathrm{~m} / \mathrm{sec}$. The device is made from a durable hardened plastic material, there are no moving parts ensuring that this is a low maintenance device, low cost durable instrument suitable for all environments and weather conditions (Princeton University, 2018). See Figure 2.

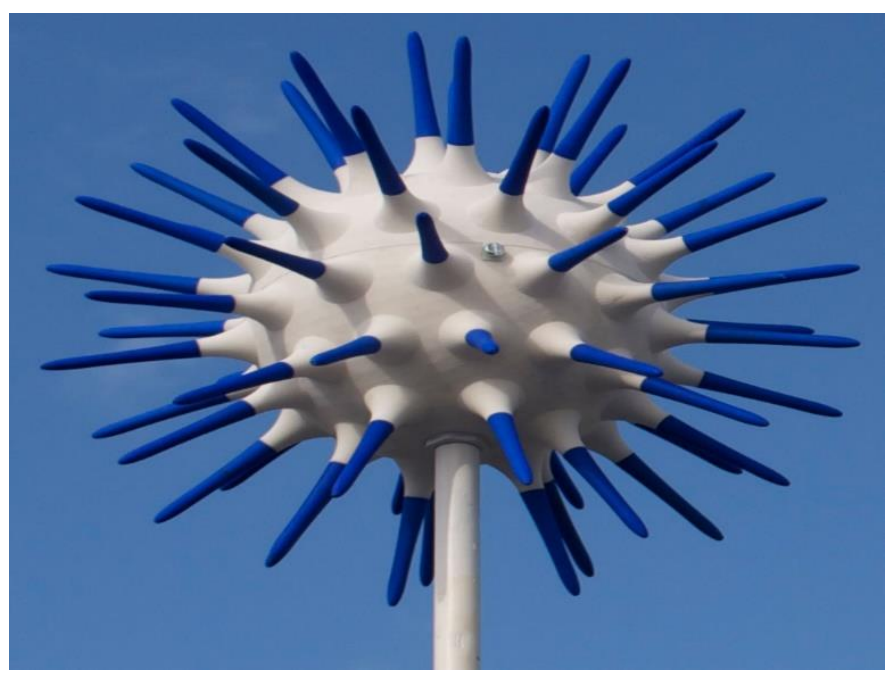

Figure 2. The Wind Urchin. Adapted from "Wind Urchin," by Energy Resource Group, 2018. Retrieved from http://www.energyresourcegroup.io/ 
The Wind Urchin is a device consisting of 64 pitot tubes orientated and positioned eqiangularly and extending radially about a sphere. The pitot tubes extend to a distance of $400 \mathrm{~mm}$ from the surface of the sphere body such that the pressure readings at the distal end or tip of each tube are taken in as close an approximation to free flow conditions as is possible. This distance has been determined as the optimum distance away from any distorted flow that is known to occur in the vicinity of the surface of any bluff body placed into a free flow stream. A pitot tube is a pressure measurement device which works by measuring a differential pressure and is used to measure fluid flow velocity. It is extensively used in the marine and aviation industries where pitot tubes are used to measure the speed of a vessel travelling through the water or to measure the airspeed of an aircraft. See Figure 3.
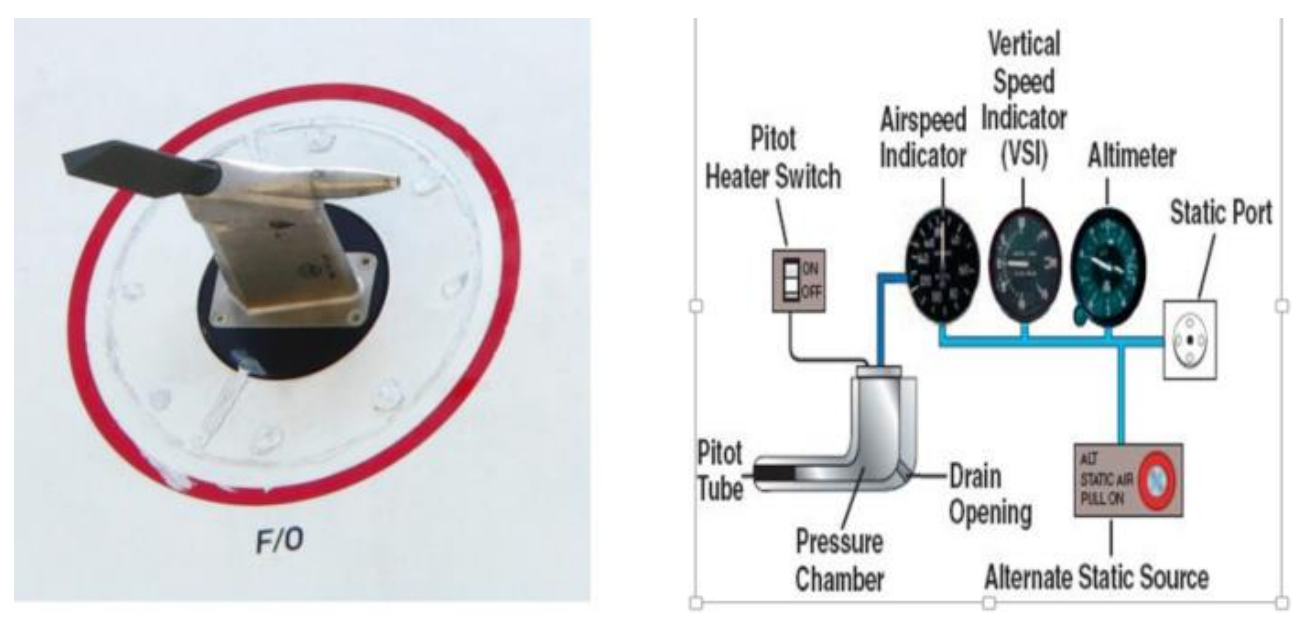

Figure 3. Pitot Tube on Airbus A380 Aircraft. Adapted from "Airspeed," by D. Monniaux, 2007. Retrieved from https://commons.wikimedia.org /wiki/ File:Airspeed_p1230157.jpg

Bernoulli's principle is also used to determine the wind speed measured by the Wind Urchin. Bernoulli's principle states that an increase in the speed of a fluid occurs simultaneously with a decrease in pressure, so pressure and density are inversely related. From this principle, the Bernoulli equation conceives of pressure as a point property that can vary from point to point throughout a fluid, from which a differential equation may be derived relating pressure and velocity. This in effect means that every point in a steadily flowing fluid, regardless of the fluid speed, has its own unique static pressure and dynamic pressure and the sum of these is defined to be the total pressure. Bernoulli's equation may be summarized in the following word equation: static pressure + dynamic pressure $=$ total pressure. In applying this to the quantity of interest - the measurement of free air flow the total pressure is the sum of the 
static or atmospheric pressure plus the dynamic pressure (the pressure caused by the moving air that is sampled at the tip of the Pitot tube where the fluid flow is brought to rest - it "stagnates"). In order to determine the fluid velocity, the fluid density must be known. The complete expression of Bernoulli's Equation (Princeton University, 2018) contains the following:

$$
\frac{v_{1}^{2}}{2}+g z_{1}+\frac{P_{1}}{\rho}=\frac{v_{2}^{2}}{2}+g z_{2}+\frac{P_{2}}{\rho}
$$

This can be used to derive a formula for converting the pressure recorded by the pressure sensors to wind speed. The overall height of the current MTP is just $3 \mathrm{~m}$ so any atmospheric pressure difference due to height is negligible so height:

$$
z_{1}-z_{2}=0
$$

This becomes:

$$
\frac{v_{1}^{2}}{2}+\frac{P_{1}}{\rho}=\frac{v_{2}^{2}}{2}+\frac{P_{2}}{\rho}
$$

$\mathrm{V}_{1}$ relates to the point where total pressure is equal to static pressure so $\mathrm{V}_{1}$ equals to zero, so:

$$
\frac{P_{1}}{\rho}=\frac{v_{2}^{2}}{2}+\frac{P_{2}}{\rho}
$$

Rearranging this equation, we get Eq.3 that relates dynamic pressure to velocity:

$$
v_{2}=\sqrt{\frac{2\left(P_{1}-P_{2}\right)}{\rho}}
$$

This equation indicates that the relationship between velocity and pressure for the system is nonlinear as illustrated in Figure 4. 


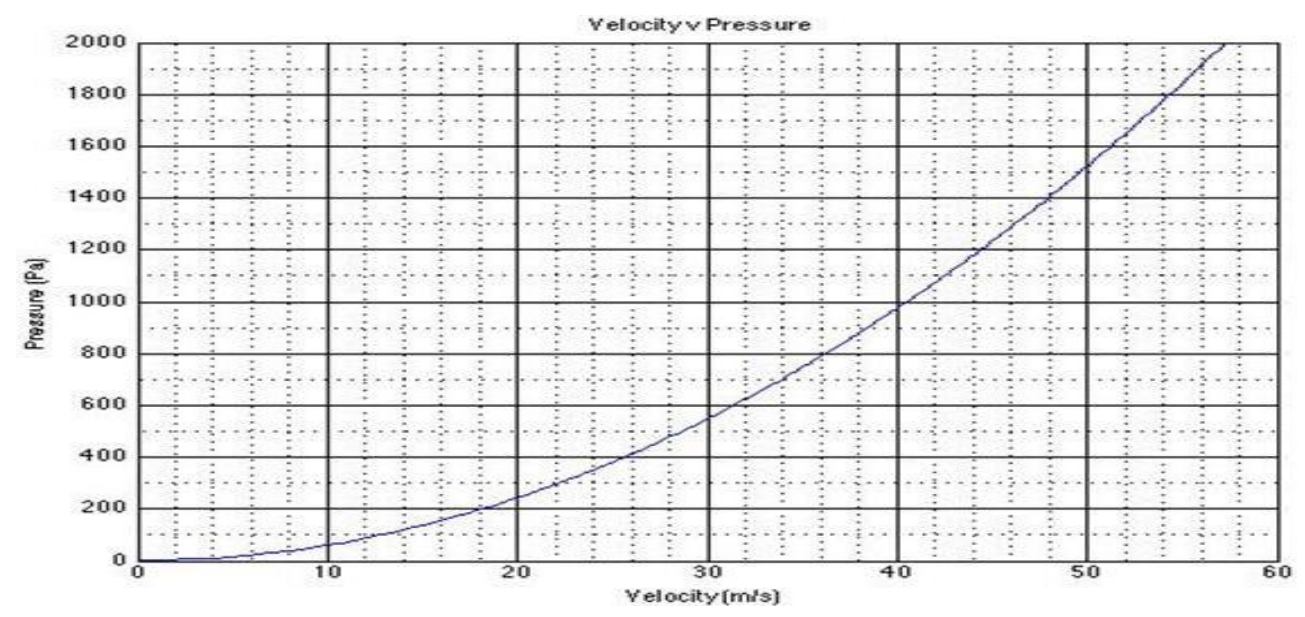

Figure 4. Conversion of Air Pressure to Wind Velocity. Adapted from "Bernoulli's Equation," by Princeton University, 2018. Retrieved from https://www.princeton.edu/ asmits/Bicycle_web/Bernoulli.html

Once the Wind Urchin is in a wind flow stream, the wind acting on the pressure tubing housing the Pitot tubes causes pressure signals propagate at a known speed through the tubes. The ends of the tubes are connected to pressure sensors known as transducers. The final equation for converting the pressure at the Pitot tube to velocity $(\mathrm{m} / \mathrm{s})$ is:

$$
v_{2}=\sqrt{2\left(\frac{V_{R I O}}{\frac{0.0068}{\rho}}\right)}
$$

Eq. 4

A reference or datum file is used to access the linear tested values of each pitot tube. As stated, a pitot tube is a device which has a differential pressure which is proportional to the square of the incident velocity. The pressure in each tube was recorded 100 times/sec and stored in a digital count. The pressure in each of the pitot tubes is linearly related to the digital count. The parameters for this relationship were stored as csv values in a file known as the baseline file. The TDMS converted file and the values of the baseline file provide two of the component files required to determine the wind pressure being applied to each of the pitot tubes. To determine the wind direction, it is necessary to know where each individual tube is located on the sphere. Each pitot tube was referenced by its location on the sphere. This was done by creating a grid map of the sphere with the longitude and latitude co-ordinates of 
International Journal of A viation, A eronautics, and Aerospace, Vol. 6 [2019], Iss. 1, Art. 3

each tube referenced with the angles measured in radians. Figure 5 depicts the plan grid map layout for the pitot tubes on the sphere. 


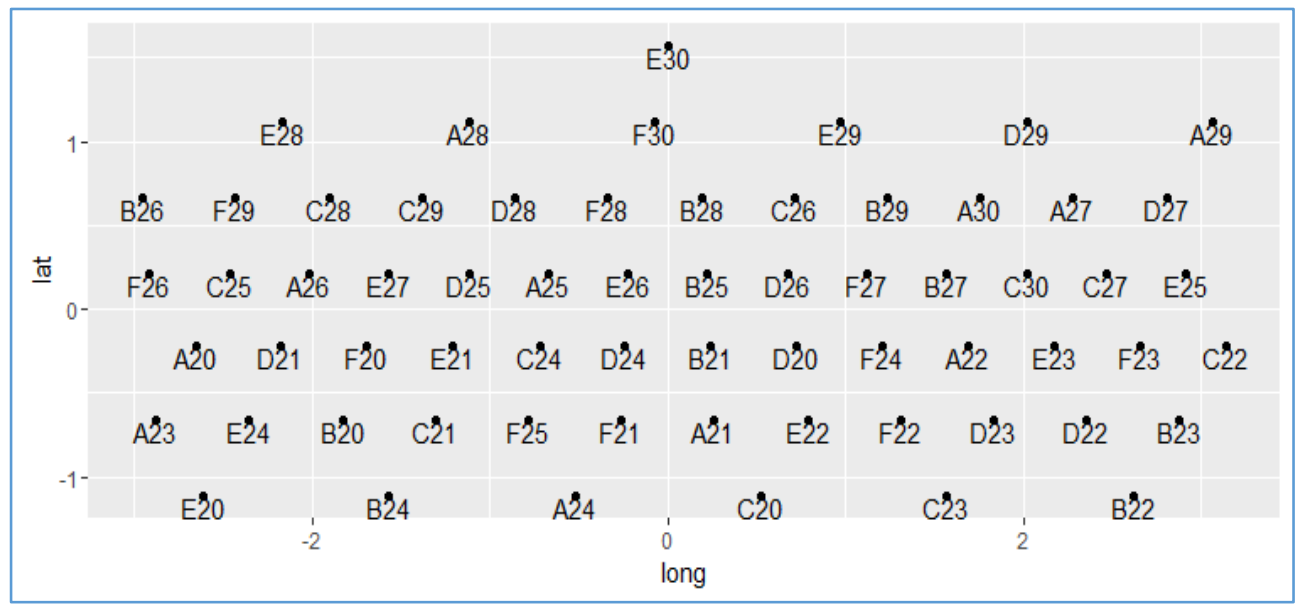

Figure 5. Pitot Tube Grid Map. Adapted from "Wind Urchin,” by Energy Resource Group, 2018. Retrieved from http://www.energyresourcegroup.io/

The data for the pitot locations on the sphere were stored in a pitot position file and the information was saved as a csv file. The three csv files are then read and computed by a computer programme using the $\mathrm{R}$ programming language. $\mathrm{R}$ programming is used extensively for statistical computing and graphical techniques including linear and non-linear modelling and time series analysis making it ideal for use with the Urchin project. An R program was written and compiled to read the data from the three csv files mentioned above, the program converts the digital counts into pressure values using the linear relationship from the parameters stored in the baseline file and calculates 1 second averages. The $\mathrm{R}$ program then determines the pitot tube with the highest pressure-value for each second interval in the sampled period. It must be noted that the sphere has a north referenced pitot tube which is aligned to magnetic north for aviation applications and true north for wind turbine alignment applications. The $\mathrm{R}$ program designates the wind direction to the values of the pitot tubes geographical location on the sphere using parameters in the pitot position file. The program designates the wind speed to the value proportional to the square root of the pitot tubes pressure differential. The program then does a non-linear least squares optimization, cantered on that designation, to determine both the velocity and direction of the wind. The program then outputs the wind speed and direction as a function of the time. Wind speed and directional data for the horizontal and vertical directions was recorded and measured for a one-month period for the anemometer and Wind Urchin, this data was analysed and graphs produced to illustrate the comparison of information from both devices. Figure 6 graphs the raw data from the anemometer for a one-month time period against the 20 second averages from the Wind Urchin. It can be seen that the graphed data from the Wind Urchin tracks closely that of the cup anemometer for the time period analysed. The 
wind speed was sampled for the same time period using 10-minute averages to analyse and compare the data from the cup anemometer and Wind Urchin.

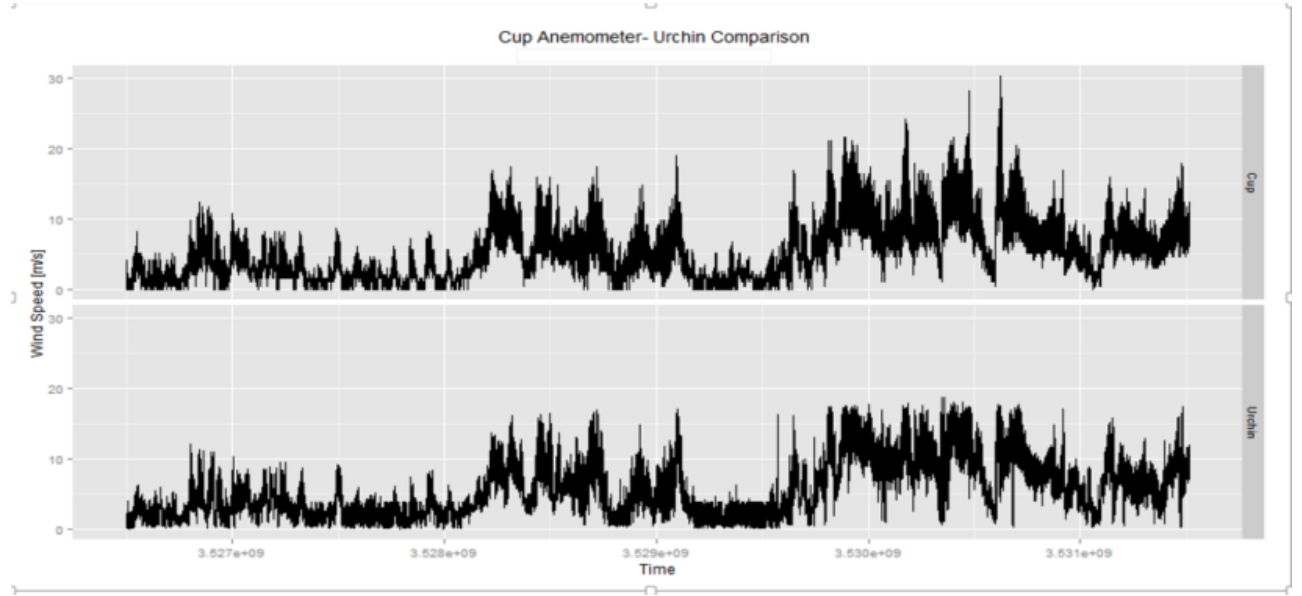

Figure 6. Cup Anemometer - Wind Urchin Comparison.

In Figure 7, the data from both instruments is output and superimposed onto a graphed display to illustrate more clearly how closely the data from each device correspond with respect to each device. The graphed data from the Wind Urchin is represented in blue while the data from the cup anemometer is represented in black. 


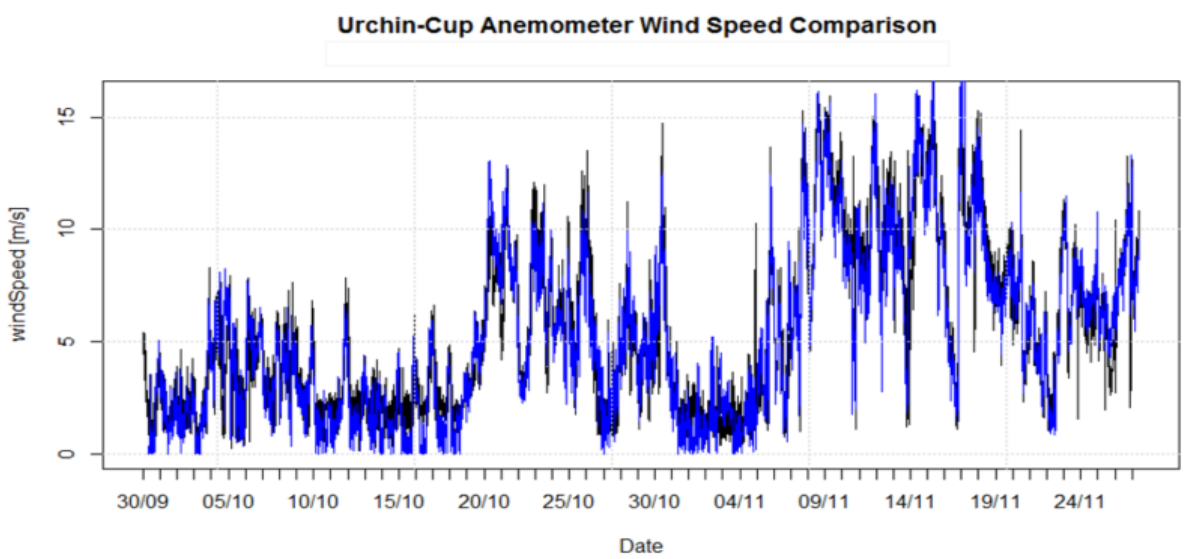

Figure 7. Wind Urchin - Cup Anemometer Speed Comparison for One Month/10-Minute Averages.

Figure 8 illustrates that the wind speed data from the Wind Urchin is measuring greater than that from the cup anemometer. This is because the Wind Urchin has recorded and averaged both the Horizontal and Vertical component of the passing wind. The cup anemometer can only measure wind in the horizontal plane, the ideal anemometer to use is one which measures total wind speed not just horizontal wind speed, and since total wind speed represents the total power of the wind. Total wind speed is required when determining the wind resource available for wind farm analyses but in the relation to the aviation sector the vertical component of wind measure is necessary to measure wind shear and microburst activity accurately at airport runway level. In Figure 8, the horizontal wind speed comparison of the Wind Urchin and cup anemometer can be seen for a one-week period measuring 10-minute averages of both instruments. 


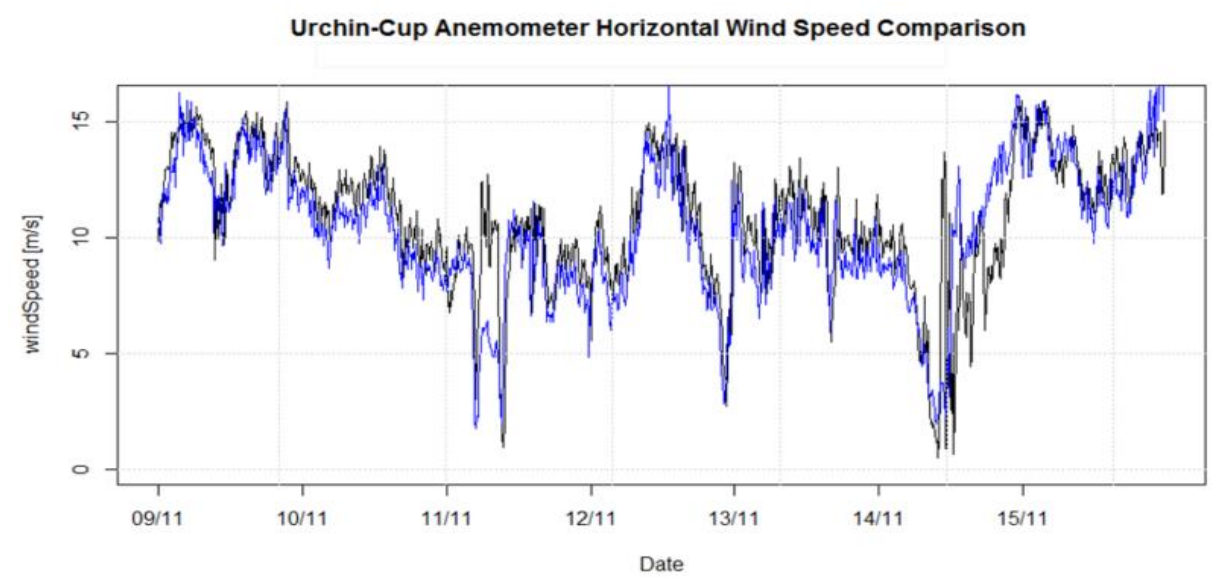

Figure 8. Horizontal Wind Speed Comparison for Wind Urchin - Cup Anemometer/10-Minute Average.

The graphed output of the analysed data from both instruments is very similar as this relates only to the horizontal wind speed component. When the vertical wind was analysed and graphed the results showed that the Wind Urchin recorded vertical wind as it passed by the stimulated pitot tubes and as expected the cup anemometer did not record the vertical wind. The graphed data for the vertical wind speed comparison for the same time period as used for the horizontal comparison for the Wind Urchin and cup anemometer can be seen in Figure 9.

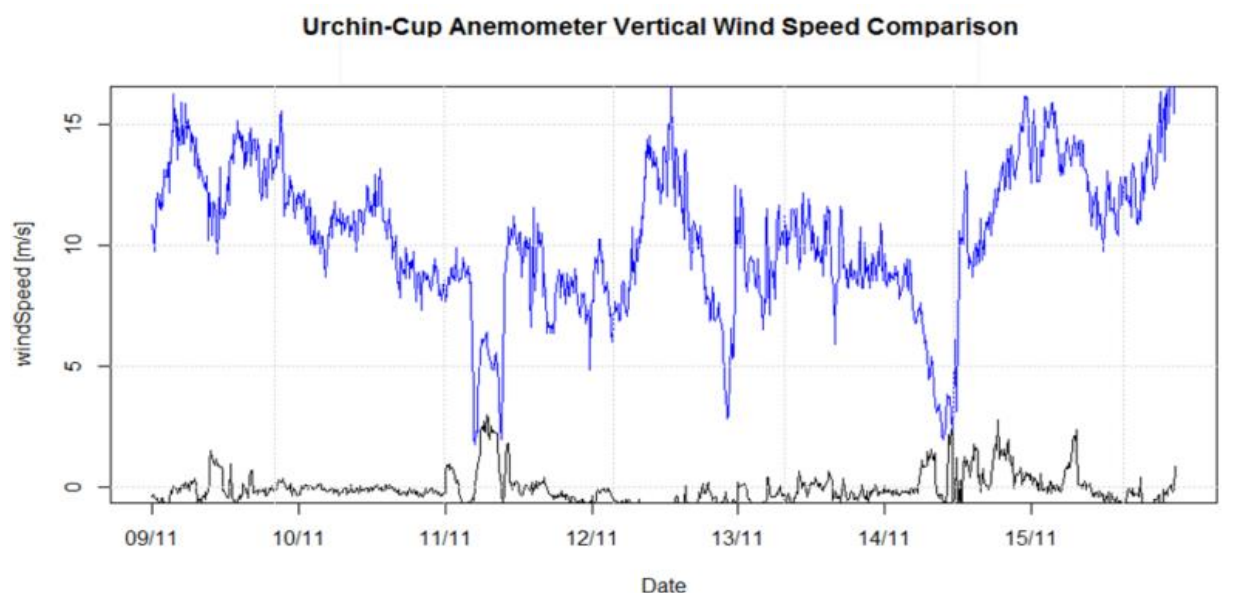

Figure 9. Vertical Wind Speed Comparison for Wind Urchin - Cup Anemometer/10-Minute Average.

In Figure 9, the Wind Urchin is represented by the blue graphed data and the cup is depicted by the black graphed data. It is very evident and clear from this illustration that the cup anemometer has not recorded any vertical wind. The Wind Urchin has recorded vertical wind in excess of $15 \mathrm{~m} / \mathrm{s}$ for the 
same time sampled 10-minute averaged period. The Wind Urchin is a highly accurate three-dimensional wind instrument with a wide measuring range to measure wind speed from $0-250 \mathrm{~m} / \mathrm{sec}$. The integration of the Wind Urchin into a LLWAS at airport runways could significantly improve the forecasting and recording of low-level wind shear and microburst activity, giving a greater POD in the network area. This as previously stated would improve safety for passengers and aircraft during the take-off and landing stages of flight. The installation and integration of the Wind Urchin into a current LLWAS could produce significant saving for the entire aviation industry. Forty-to percent of all go-arounds are as a result of wind conditions, the direct cost of go-arounds have been researched and quantified by the author. The researched evidence concluded that hundreds of millions of Euro per annum could be saved if better real time wind shear data was available to pilots when on approach to landing. This could avoid wind associated go-arounds manoeuvres on approach to landing.

\section{Conclusions}

Finding from this research have established that low-level wind shear and turbulence present a serious safety risk to aircraft during the approach, landing and take-off phases. Low-level wind shear has been identified as one of the primary factors for aircraft go-arounds and aborted landings. Aviation reports have concluded that pilots do not always have real time up to date information about low-level wind shear and turbulent conditions at runway level. Pilots need to have improved information in relation to tailwinds, wind shear and wind variations on approach and during the landing phases. The aviation industry concluded that the majority of accidents that occurred over the past 10 years have occurred during the approach, landing and go-around flight phases. At the go-around safety forum in Brussels in 2013, it was concluded that due to rapid changing weather and runway conditions, a pilot does not always have the latest information on which to make a landing or go-around decision (Eurocontrol, 2013). Air accident reports have stated that between 2000 and 2012 there were 10 fatal accidents attributed to flight go-arounds in which 614 people died. Current methods of wind shear calculations involve data from an aircraft on descent and recording data from different anemometer spaced at different levels along a runway of mast. The limitation in this approach is that the calculation of wind shear from two winds separated by a distance gives the overall wind shear between those two points. The information does not indicate if the rate of shear is linear or not or where most of the shear occurs between the points sampled. It is wholly inadequate and does not give the maximum shear. 
Extreme low-level wind shear and turbulence can at its worst cause and aircraft to crash resulting in fatalities and injuries to passengers and crew and destruction or damage to an aircraft. At the lower end of the scale, wind shear and turbulence will result in delays to take offs and landings, aborted landings resulting in flight go-around manoeuvres or flights being diverted to another airport. According to the U.S. Department of Transportation records from the National Aviation System (NAS), 33\% of all delayed flights in 2016 were delayed due to weather conditions. The figure for 2017 was over $50 \%$ due to weather conditions (Kroepl, 2013). The IATA concluded that the actual wind conditions versus the recorded and reported wind conditions given to the flight crew on final approach were an area of concern. It has been established that low-level wind shear and turbulence account for $42 \%$ of all go-around procedures being initiated by pilots (Kroepl, 2013).

It has been established that over $78 \%$ of all go-arounds were initiated by the flight crew and $22 \%$ were initiated by the Air Traffic Control (ATC) . This would seem to indicate the wind shear and turbulence data recorded by the ATC was not accurate or up to date for the approaching aircraft and it was the flight crew who deemed it necessary to abort the landing based on the conditions that they encountered on approach. The research has found that when a Go-around manoeuvre is undertaken that most commercial airline pilots, did not have sufficient experience or training in how to handle an aircraft during a go-around caused by a wind shear event resulting in fatalities. The research has gathered information to calculate accurately the direct Go-around cost incurred by two of most used medium range aircraft in operation today. The research has found that the current conservative estimate for global Go-arounds annually is in excess of $€ 558$ million and by the year 2036 will exceed $€ 1$ billion in direct costs alone (O'Connor, 2018). The financial cost to aviation alone would justify the installation and integration of a new 3-D wind measuring instrument into an existing low-level wind shear alert system. Beta tests from the Baldonell aerodrome have shown that the Wind Urchin recorded the vertical wind component providing the total wind speed at the airport runway while the graphs illustrated that the runway anemometers did not record any vertical wind. The ability to detect the vertical wind component accurately is essential for tracking and recording microbursts. The research and findings of this paper have established that despite major advances in microburst detection and low-level wind shear detection at runway level with Terminal Doppler Weather Radar, Doppler Lidar, Weather Surveillance Radar, and LLWAS, there continue to be incidents, accidents, and go-arounds as a result of low-level wind shear and microbursts. All of the above systems are costly to install, maintain, service and upgrade. Most large commercial airports have at least two, three of all of the above systems installed to provide microburst and Low-level wind shear alert coverage.

In contrast the Wind Urchin is a low cost, low maintenance robust device. The Wind Urchin is the world's first truly three-dimensional instrument 
that measures wind in all its aspects. It has been established that integrating the Wind Urchin into an existing LLWAS around the airfield extended boundary would not pose any technical difficulty as the protocols and interface of the Wind Urchin can be easily integrated into current systems. The Wind Urchin could theoretically replace all the current ultrasonic sensors within a LLWAS. The Wind Urchin can provide a much greater sampling rate than any other anemometer currently used in aviation for a specific timeframe. The ability of the Wind Urchin to measure both horizontal and vertical wind components would ensure that more accurate and up to date data is available to the ATC in determining if an aircraft should abort a take-off or initiate a go-around. The Hong Kong Observatory's future development plan is for an uplink of textual and graphical wind shear and warning data directly to the cockpit (Hong Kong Observatory, 2018). This would cut out the delay of data being transmitted to the flight crew by the ATC and provide a quicker transfer of the recorded wind data at runway level to the pilot. If the Wind Urchin was then integrated into the LLWAS, not only would the upload of data be faster but more importantly, it would be a more accurate and complete profile of current runway wind conditions. This would provide the pilot with the latest and most accurate runway wind data enabling the pilot to determine the best course of action for any given wind situation. Figure 10 illustrates how the Wind Urchin could integrate into any future LLWAS.

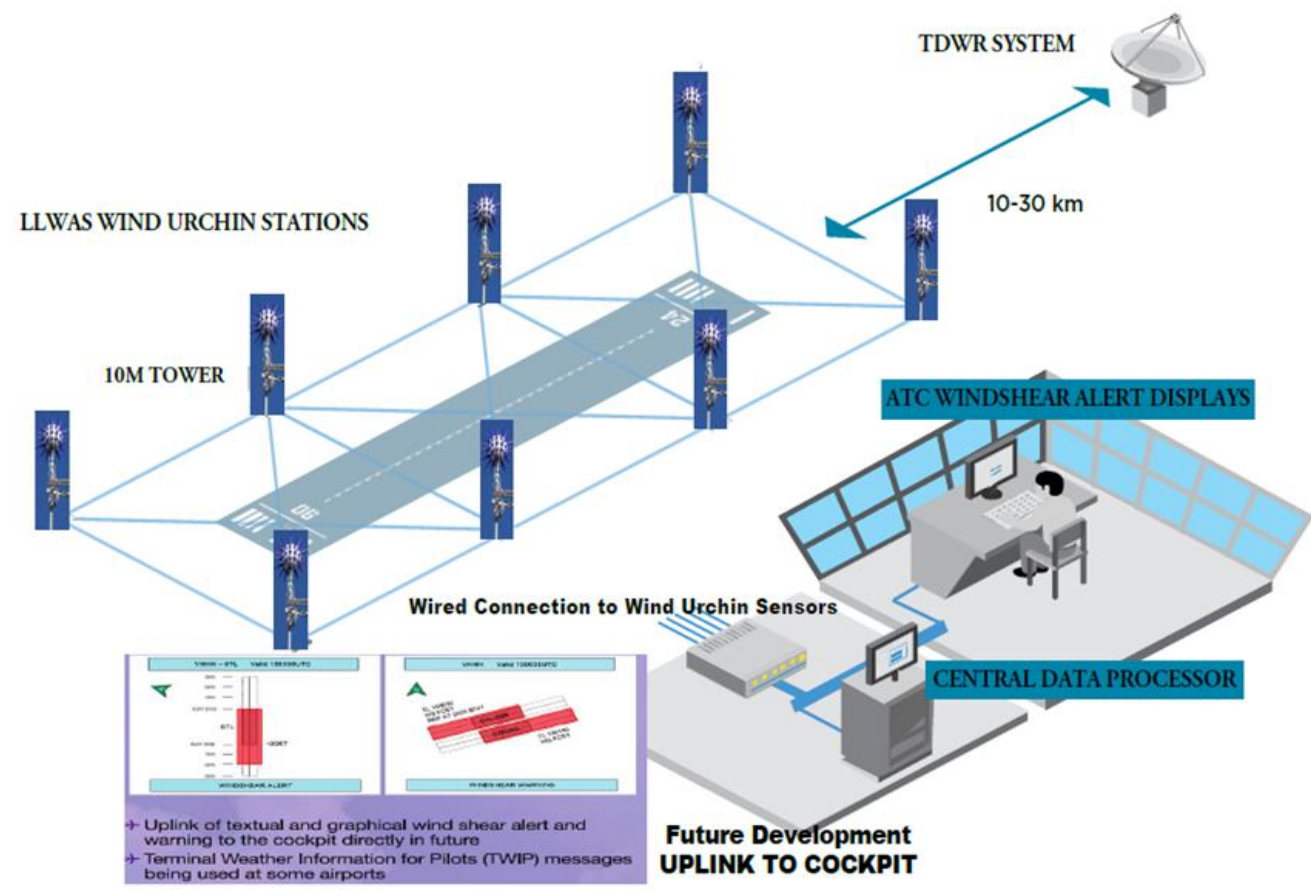

Figure 10. Concept of a Future LLWAS Incorporating the Wind Urchin. 
International Journal of Aviation, Aeronautics, and Aerospace, Vol. 6 [2019], Iss. 1, Art. 3

The benefits over existing LLWAS sensors are increased sampling rate of wind data, measurement of the total wind power at runway level, recording and measurement of horizontal and vertical wind data. Currently, LLWAS can only provide textual data to the ATC wind alert display as shown in Figure 11. 


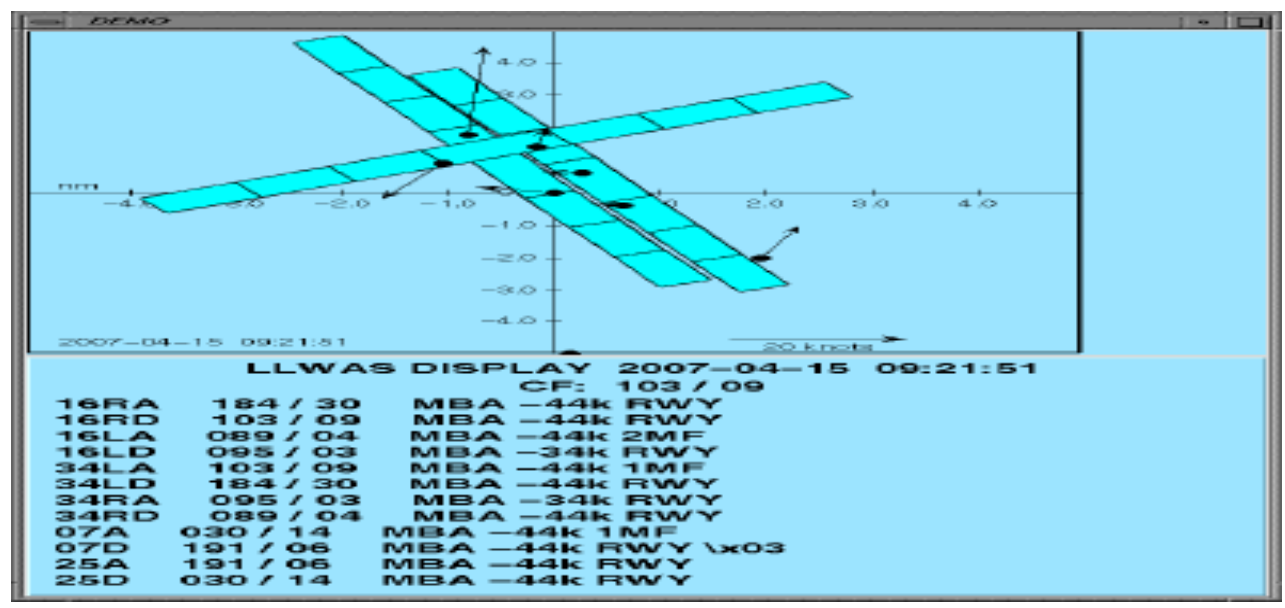

Figure 11. LLWAS ATC Monitor Display. Adapted from "ICAO Wind Shear Systems Acquisition Workshop," by Centre for Australian Weather and Climate Research, 2010.

The Wind Urchin data can produce a 3-D image map similar to those produced by TDWR and Lidar systems making it easy to interface to the airport AWOS. Figure 12 illustrates the 3-D image of the wind intensity on the surface of the Wind Urchin.

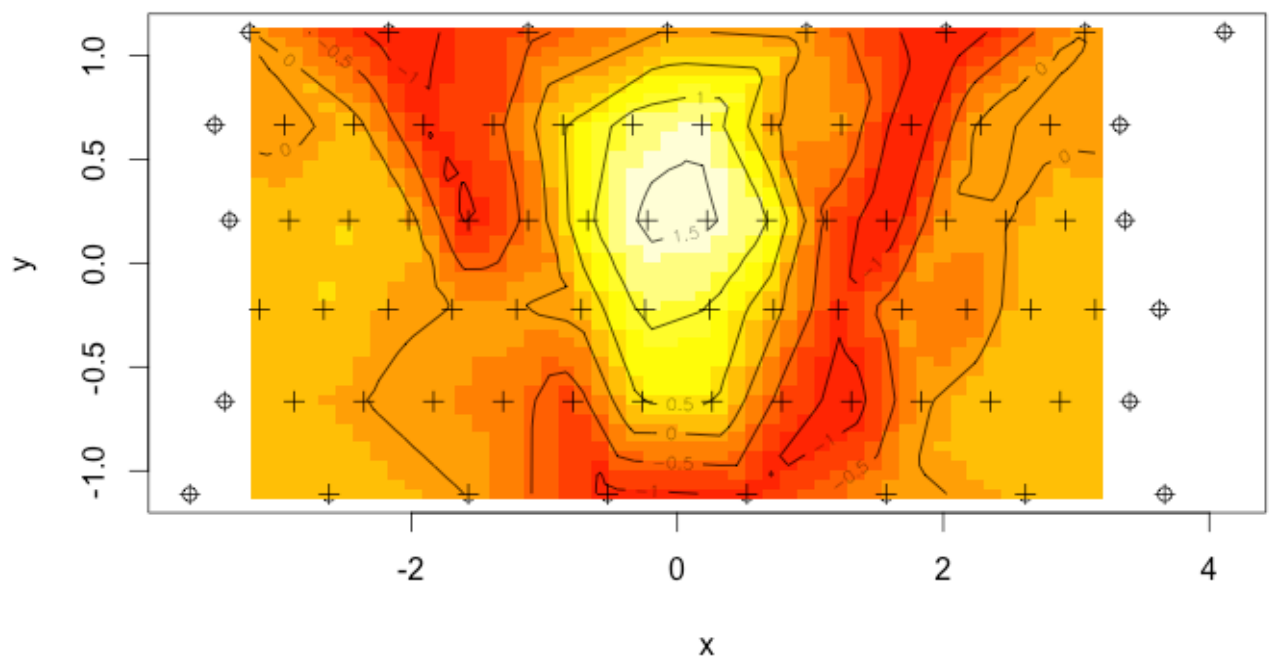

Figure 12. 3-D Image of Wind Intensity on the Surface of Wind Urchin. Adapted from "Wind Urchin," by Energy Resource Group, 2018. Retrieved from http://www.energyresourcegroup.io/ 
Incorporating the Wind Urchin into current LLWAS at terminal boundary areas could improve safety for passengers and aircraft. The thesis has shown that it has the potential to save millions of Euro annually in direct cost for Go-arounds. The Wind Urchin is a commercially viable device increasing safety and reducing costs for the aviation industry. Incorporating the Wind Urchin into existing LLWAS coupled with a wind shear alert and warning uplink to the cockpit could provide the missing ingredient to existing systems to give an airport runway a Prediction of Detection Rate of close to $100 \%$.

\section{ACKNOWLEDGMENT}

The research reported in this paper is supported by Dublin Institute of Technology and the Energy Resource Group. The wind velocity data provided for the study was provided by the Energy Research Group and Dr Derek Kearney. The Author would like to thank the researchers in the ERG for their support and in particular Dr Derek Kearney for assisting with this paper.

\section{FURTHER RESEARCH}

The research gathered during the course of the research would suggest that there is a gap in the ability of current systems to provide a total low-level wind shear alert system that can provide real time up accurate up to date information to pilots. The beta tests carried out at Baldonell aerodrome have shown the ability of the Wind Urchin to detect and measure wind as a 3-D entity, graphing its horizontal and vertical components. Ideally, four Wind Urchin's would need to be developed and constructed to obtain wind data from different points along an airport runway. This would give comparison data against each other and installed runway instruments. Vaisala has suggested that in order for the Wind Urchin to be considered for use in the aviation sector that a 3-D microburst simulation be carried out. The WMO has strict requirements for surface wind measurement and has set guidelines for surface weather measurements to ensure comparable measurement around the globe (WMO, 2010). The ICAO, Meteorological Service for International Air Navigation has set requirements for instruments used to record meteorological data for use in the civil aviation industry (ICAO, 2007). The FAA require additional certification in addition to the WMO and ICAO for instruments used for the purpose of wind surface measurement (FAA, 2015). After completion of 3-D microburst simulations, it is proposed that an approach be made to a LLWAS provider to further evaluate the Wind Urchin for integration into an existing system and compliance with all relevant aviation requirements and standards. 


\section{REFERENCES}

Allweatherinc. (2018, February 23). Low-level wind shear alert system. Retrieved from allweatherinc: http://www.allweatherinc.com/Lowlevel-wind-shear-alert-system/

Aviation Safety Network. (2018, February 13). ASN aviation safety database. Retrieved from Flight Safety Foundation: http://aviation-safety.net/ database/ dblist.php? Event $=$ WXW\&lang $=\&$ page $=1$

Centre for Australian Weather and Climate Research. (2010). ICAO wind shear systems acquisition workshop. Bangkok: Centre for Australian Weather and Climate Research.

Chan, S. C. (2005). Briefing on windshear and turbulence alerting service S.T. Chan \& P.W. Hong Kong: Hong Kong Observatory.

Cho, R. G. (2010). Wind-shear system cost-benefit analysis. Lincoln Laboratory Journal, 68.

Energy Resource Group. (2018, May 2). Wind urchin. Retrieved from http://www.energyresourcegroup.io/windurchin

Eurocontrol. (2013). Go-around safety forum. Brussels: Flight Safety Foundation.

Federal Aviation Administration. (2015, September 30). Advisory circular 150-5300-18C. Retrieved from https://www.faa.gov/documentLibrary/ media/ Advisory_Circular/ 150-5300-18C.pdf

Federal Aviation Administration. (2016). Pilots handbook of aeronautical knowledge. Oklahma City, OK: Author.

Gill Instruments. (2018, February 19). Wind observer used at airports. Retrieved from http://gillinstruments.com/applications/transport-traveland-buildings/airport-aviation-wind-measurement.html

Hong Kong Observatory. (2018, February 21). Windshear and turbulence alerts. Retrieved from http://www.hko.gov.hk/ aviat/amt_e/ windshear_warning_e.htm

Internation Civil Aviation Organization. (2005). Manual on low-level wind shear. Montréal, Canada: Author.

Internation Civil Aviation Organization. (2007). Annex 3 to the convention on international civil aviation: Meteorological service for internanational air navigation. Montréal, Canada: Author.

John Y. N., \& Cho, R. G. (2008). Comparative analysis of terminal windshear detection systems. Lexington, MA: American Meteorological Society.

Kroepl, M. (2013, June). Go-arounds. Retrieved from https://www.skybrary.aero/bookshelf/ books/2307.pdf

Monniaux, D. (2007, June 20). Airspeed. Retrieved from https://commons.wikimedia.org/wiki/File:Airspeed_p1230157.jpg

National Oceanic and Atmospheric Administration. (2018, March 5). Radar operations centre: Nexrad WSR-88D. Retrieved from 
https://www.roc.noaa.gov/wsr88d/ Engineering/

NEXRADTechInfo.aspx

National Weather Service. (2013, December 10). Improving the VWP. Retrieved from https://www.roc.noaa.gov/ wsr88d/PublicDocs/ NNOW/NNDec2010/3-5.pdf

O'Connor, A. (2018, Nov 15). Evaluating the effect of turbulence on aircraft during landing and take-off phases. Retrieved from https://commons.erau.edu/ijaaa/vol5/iss4/10/

Office of Aviation Weather Observations. (2010). Wind shear detection systems in Japan. Tokyo, Japan: Japan Meteorological Agency.

Princeton University. (2018, May 24). Bernoulli's equation. Retrieved from https://www.princeton.edu/ asmits/Bicycle_web/Bernoulli.html

U.S. Department of Commerce. (2006). Doppler radar meteological observations. Retreived from https://www.ofcm.gov/publications/ fmh/FMH11/fmh-11B-2005.pdf

WMO. (2016). Doppler radar for airport weather. Retrieved from WMO: https://www.wmo.int/pages/prog/www/IMOP/meetings/Upper-Air/ETRSUATT-2/Doc-6-3_2.pdf 